\title{
TAXONOMIC FLUX AS A MEASURE OF EVOLUTIONARY TURNOVER
}

\author{
W. Gray DEAN' and Michael L. McKINNEY \\ Department of Geological Science. University of Tennessee. Knoxville. \\ Tennessee 37996. ' graydean@utkux.utcc.utk.edu
}

\begin{abstract}
Dean, W.G. and McKinney, M.L. 2001. Taxonomic flux as a measure of evolutionary turnover. [El flujo taxonómico como una medida del reemplazamiento evolutivo.] Revista Española de Paleontología, 16(1), 29-38. ISSN 0213-6937.
\end{abstract}

\begin{abstract}
We introduce a new metric, "taxonomic flux", to quantify evolutionary trends both within and across taxonomic boundaries. This metric is normalized, which reduces the effect of sample size disparity between biologic groups and time intervals. Furthermore, this methodology considers stratigraphic range data as a whole, and measures relative growth or decline of diversity values as they deviate from system stability. Such trends may yield key information relating to evolutionary processes and forcing functions, especially if these trends are correlative within particular taxa or niche occupancy. Thus far, scientists and researchers have been stymied by absolute values derived from unequal datasets and by metrics designed only to quantify limited aspects of evolutionary dynamics. It is the purpose of this paper to demonstrate the utility of taxonomic flux both theoretically and from empirical study examining several invertebrate orders belonging to the classes Echinoidea, Bivalvia and Gastropoda. Taxonomic flux is an adaptable metric applicable to various levels of the taxonomic and ecological hierarchy thus enabling comparisons of the palaeontological record with that of the Recent.
\end{abstract}

Keywords: Cenozoic, biodiversity metrics, invertebrates, stasis, volatility.

\section{RESUMEN}

En este trabajo se propone una nueva medida, denominada "flujo taxonómico", que permite cuantificar las tendencias evolutivas tanto en el seno de los clados como para comparar la dinámica mostrada por diferentes entidades taxonómicas. Tal métrica se presenta normalizada, lo que reduce el efecto de la disparidad en tamaño muestral entre grupos biológicos e intervalos temporales. Más aún, esta metodología considera en conjunto los datos sobre rangos estratigráficos y proporciona estimaciones sobre crecimiento relativo o el declive de los valores de diversidad según estos se desvíen respecto a la estabilidad del sistema. Tales tendencias pueden entonces suministrar información clave en relación con los procesos evolutivos y las fuerzas o factores que los moldean, especialmente si las tendencias se correlacionan en el seno de categorías taxonómicas concretas o implican la ocupación de determinados nichos ecológicos. Hasta el momento, los investigadores que se ocupan del tema se han visto obstaculizados por el uso de valores absolutos derivados de bases de datos no necesariamente equivalentes y medidas que se diseñaron con vistas a cuantificar solo aspectos limitados de la dinámica evolutiva. El propósito de este artículo es demonstrar la utilidad del flujo taxonómico tanto desde un punto de vista puramente teórico como a partir de un estudio empírico en el que se examinan varios órdenes de invertebrados, pertenecientes a las clases Echinoidea, Bivalvia y Gastropoda. El flujo taxonómico es, pues, una medida adaptable, que puede aplicarse a varios niveles de las jerarquías taxonómica y ecológica, permitiendo así efectuar comparaciones del registro paleontológico con el actual.

Palabras clave: Cenozoico, medidas de biodiversidad, invertebrados, estasis, volatilidad.

\section{INTRODUCTION}

There are many ways to analyse evolutionary turnover (McKinney and Drake, 1998). Unfortunately, however, the palaeontological record exists, for the most part, as an incomplete dataset (Koch, 1991). Thus, comparisons of evolutionary trends between taxonomic groups are limited when using metrics centred about absolute values derived from the stratigraphic record (Jablonski, 1995). Most evolutionary metrics, such as proportional extinction or speciation are fractions, and are controlled by the value of the denominator. In most instances, this is 


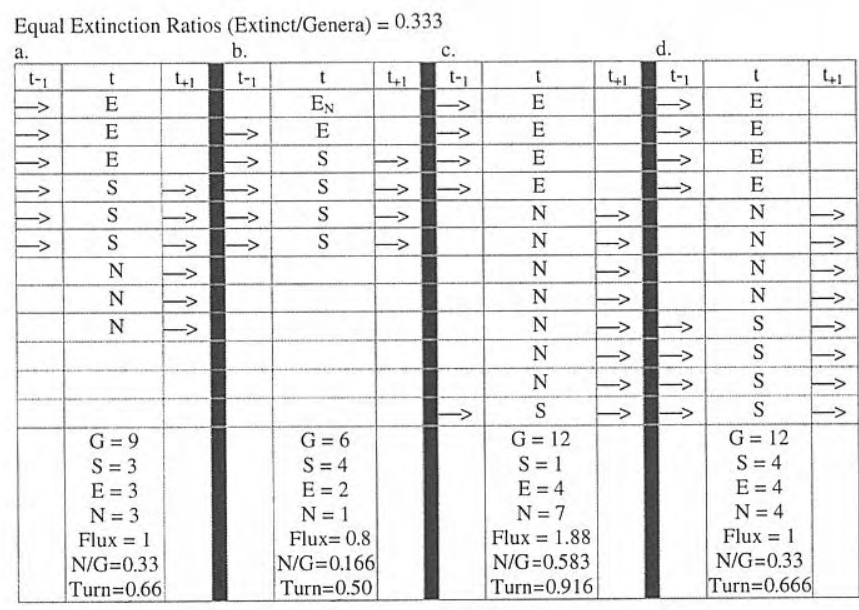

\begin{tabular}{|c|c|c|c|c|c|c|c|c|c|}
\hline \multicolumn{10}{|c|}{$\begin{array}{l}\text { Equal Speciation Ratios (New/Genera) }=0.66 \\
\text { e. } \quad \text { f. }\end{array}$} \\
\hline$t-1$ & $\mathrm{~T}$ & $t-1$ & $t$ & $t_{+1}$ & $t-1$ & t & \begin{tabular}{|l|l|}
$t+1$ & $t-1$ \\
\end{tabular} & $t$ & \\
\hline & $\mathrm{N}$ & $\rightarrow$ & $\mathrm{N}$ & $\rightarrow$ & $\rightarrow$ & E & $\Rightarrow$ & E & \\
\hline & $\mathrm{N}$ & $\Rightarrow$ & $\mathrm{N}$ & 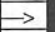 & $\rightarrow$ & $\mathrm{S}$ & & $\mathrm{N}$ & $\Rightarrow$ \\
\hline & $\mathrm{N}$ & $\Rightarrow$ & $\mathrm{N}$ & 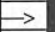 & & $\mathrm{E}_{\mathrm{N}}$ & & $\mathrm{N}$ & $\Rightarrow$ \\
\hline & $\mathrm{N}$ & $\rightarrow$ & $\mathrm{N}$ & $\Rightarrow$ & & $\mathrm{E}_{\mathrm{N}}$ & & $\mathrm{N}$ & $\Rightarrow$ \\
\hline$\Rightarrow$ & E & & $\mathrm{E}_{\mathrm{N}}$ & & & $E_{N}$ & & $E_{N}$ & \\
\hline$\Longrightarrow$ & $\mathrm{S}$ & $\Longrightarrow$ & $\mathrm{E}_{\mathrm{N}}$ & & & $\mathrm{E}_{\mathrm{N}}$ & $\Rightarrow$ & S & $\Rightarrow$ \\
\hline & & $\Rightarrow$ & $\mathrm{S}$ & $\Rightarrow$ & & & & & \\
\hline & & $\Rightarrow$ & $S$ & $\mapsto$ & & & & & \\
\hline & & $\Longrightarrow$ & E & & & & & & \\
\hline & & & & & & & & & \\
\hline & $\mathrm{G}=6$ & & $\mathrm{G}=9$ & & & $\mathrm{G}=6$ & & $\mathrm{G}=6$ & \\
\hline & $S=1$ & & $S=2$ & & & $S=1$ & & $S=1$ & \\
\hline & $E=1$ & & $\mathrm{E}=3$ & & & $E=5$ & & $E=2$ & \\
\hline & $\mathrm{N}=4$ & & $N=6$ & & & $N=4$ & & $\mathrm{~N}=4$ & \\
\hline & Flux $=2.2$ & & Flux $=1.83$ & & & Flux $=0.73$ & & $\left|\begin{array}{l}\text { Flux }=1.8 \\
\mathrm{~F} / \mathrm{G}=0.33\end{array}\right|$ & \\
\hline & $\begin{array}{l}E / G=0.166 \\
T \text { Turn=0.83 }\end{array}$ & & $\begin{array}{l}\mathrm{E} / \mathrm{G}=0.333 \\
\text { Turn }=1.0\end{array}$ & & & $\begin{array}{l}\mathrm{E} / \mathrm{G}=0.833 \\
\text { Turn }=1.5\end{array}$ & & Turn $=1.0$ & \\
\hline
\end{tabular}

Figure 1. Hypothetical stratigraphic range chart depicting genera $(\mathrm{G})$ flowing through timesteps $t_{-1}, \mathrm{t}$, and $\mathrm{t}_{+1}$. In each instance (a-h) we are tabulating dynamics for time t. The various dynamics shown are: New originations which persisted $(\mathrm{N})$; previously existing genera which became extinct $(\mathrm{E})$; stable genera which endured no change (S); and new originations which became extinct in the same time interval $\left(E_{N}\right)$. Please note that many combinations of biotic dynamics can be reduced to the same proportional extinction ratio (a-d) and that many combinations of biotic dynamics can also be depicted as the same proportional speciation ratio (e-h). These differing combinations of $\mathrm{N}, \mathrm{S}$ and $\mathrm{E}$ are better described by taxonomic flux, which yields specific diversity values than by proportional metrics, which result in non-unique percentages that are controlled partly by sample size. Included with these values are also the calculated extinction or speciation ratios as well as turnover, (Turn) for each combination of stratigraphic data.

usually the total number of taxa observed. For example, Figure 1 depicts a hypothetical stratigraphic range chart for imaginary taxa (genus-level dynamics will be the taxonomic focal point throughout this paper) moving through time intervals, denoted $t-1, t$, and $t+1$. In each case we are calculating data for time t. Equal extinction ratios are observed in (a-d); equal speciation ratios seen in $(\mathrm{e}-\mathrm{h})$. In each situation, it is apparent that many combinations of values can ultimately be reduced to the same per cent value of proportional extinction and speciation. While these differing data, though, do yield equal extinction or speciation values they are describing differing evolutionary dynamics. This is due to several reasons. First, the data sets are not equal, we have only reduced the fractional values to the same number. Second, and more importantly, there are other dynamics depicted in each scenario that are not captured by simple extinction/speciation metrics that analyse but one parameter. Third, metrics which combine several parameters, such as turnover (extinction + speciation), may actually inflate values, as will be discussed later. Often at the precision of stratigraphic data, taxa may originate and subsequently become extinct within the same time step. Thus, it is our position that evolutionary dynamics can be captured as a numerical increase or decrease of taxa, relative to the stable members which persisted through a time interval.

The unequal biases that affect palaeontologic data include differential trends in taphonomy, exposure and collection, all of which contribute to sample size variation (Raup, 1991). Since these sample size variations are differential between taxa as well as time intervals, there is no consistent means to "correct" for missing data (Jablonski, 1995). So, while the evolutionary record is contained within the rocks, it remains difficult to interpret especially when comparing trends between biotic groups which are usually unequal datasets. This is simply because absolute values of proportional change are only meaningful if we can accurately quantify taxonomic abundance. Thus, for comparative study across taxonomic or temporal boundaries, the data must be modified somewhat (Jablonski, 1995) to correct for sample size variation and incompleteness (Palmqvist, 1993). Such manipulations can, however, lead to interpretations that are potentially biased by the assumptions used to adjust sample set variations (McKinney, 1995).

Each hypothetical taxa in Figure 1(a-d; e-h) has differing values of not only of total genera $(\mathrm{G})$, but of stable members (S) as well as variations in extinct (E) and new origination $(\mathrm{N})$ members. Thus, while we can compute an equal value for some identified parameter, we are not adequately describing the whole of evolutionary dynamics endured by these taxa. Furthermore, though we attribute much of the uncertainty to unequal datasets, when computing extinction/ speciation values, we can see that even if datasets are equal in terms of absolute size and of one particular dynamic (Fig. 1c and d; g and h), the other parameters can, and usually do, vary.

\section{BACKGROUND}

Most evolutionary research focuses only on extinction values (e.g. Sepkoski, 1995); other studies concentrate on new originations in the fossil record (McGhee, 1996). 
Occasionally, some research does consider both new originations and extinctions together (Gilinsky and Good, 1991; Russell, 1998; Eble, 1999); however, these values are not easily compared, even within taxonomic groupings. This may be due to the close approximation between the New and Extinct values which has often been observed (Stanley, 1990; Raup, 1991). A converse approach to those stipulated above, quantifies the stable component of taxa, over time (Rosenzweig and McCord, 1991). Stability is also measured as a discrete absolute value, independent of other signals found in stratigraphic range analysis (Fig. 1).

A recent paper by Demetrius (1997) suggests that biologic systems and evolution must operate within simple physical laws. This implies that for every action, there must follow opposite reaction, codified by inertia. In the case of evolution, such action may include environmental forcing functions and biotic interaction which causes reaction in terms of extinction and/or speciation. The effect of system inertia within a taxonomic grouping may be stasis, or, system stability. Furthermore, such stability may be extended to entire communities as coordinated stasis (Brett et al., 1996). It is fair to note, that the reduction of evolution into action, reaction or inertia is, by far, simplification of complex processes. Other factors such as developmental constraints (McKinney, 1990), mass extinctions, or radiation into new morphospace all influence diversity trends. This research, however, addresses the fact that most methodology seeks only to quantify a partial aspect of evolution, such as extinction or speciation (McGhee, 1996). These types of approaches are fundamentally unsound because: 1) the fossil record is incomplete, thus negating the use of absolute values; and, more importantly; 2) evolutionary dynamics are more complex than can be described by one parameter. Since biotic systems are not exempt from the physical laws, we must incorporate the total aspects of dynamical change observed in stratigraphic databases.

In a simple stratigraphic range chart (Fig. 1), we see that aside from database size $(\mathrm{G})$, there are the changes, or not, which we need to consider: Extinction (E), New origination $(\mathrm{N})$ and the Stable components $(\mathrm{S})$ which existed both before and after the time interval in question. Therefore, though the data itself may be numerically incomplete, the impetus of this research is to describe evolutionary processes and physical pathways as completely as possible.

The concept of taxonomic flux, as described here, centers about physical response of biota (i.e. extinction or speciation) as it deviates from system stability. Thus, under a mass balance approach, the number of taxa entering a timestep must be equal to the number of taxa exiting a timestep for diversity to be completely stable. Any perturbation in new or extinct values is depicted as net growth or decline, respectively. And since palaeontological data is incomplete, the dynamics are assessed as relative change rather than absolute change. This metric, however, does not consider the ecologic roles of the various taxa, nor the effects of population density. Instead, we assess the evolutionary dynamics of a particular clade. Thus, the goal for this metric is to present a means by which to measure relative change between taxa and between time intervals. We do this simply by using system stability as a baseline for assessing biotic changes.

\section{THE MODEL}

Taxonomic flux was not derived from pre-existing equations, but rather, conceived and designed to fulfill several constraints. First, under the premise of mass balance, input must equal output if a system is to be considered as stable. Second, extinction should be weighed against new originations such that stability can still be met if extinct and new taxa are equal. Third, both of the first items, input/output and new/extinct parameters are to be considered together, and not exclusive of one another. Fourth, that data size does not significantly alter results; that biases between new originations and extinctions are randomly distributed. And lastly, that the numerical results are mathematically and biologically reasonable and capture the true dynamics of relative change experienced by some biotic system.

The parameters of this metric are easily obtained from typical stratigraphic range data (Fig. 1). The configuration of this data, however, centers about normalizing for data set size $(G)$, then measuring the divergence from system stability $(\mathrm{S})$. An important consideration for this metric is that while growth and decline proceed in opposite directions, the magnitudes between them cannot always be equal. System growth can be any value, since speciation may proceed at exponential rates and exceed $100 \%$. However, extinction, or decline can never exceed $100 \%$, in which case, flux ought to be zero. Thus, by calibrating diversity divergence from stability, and allowing input $(\mathrm{G}-\mathrm{N})=$ output $(\mathrm{G}-\mathrm{E})$ to be 1 , or unity, we have a metric which meets the conditions stipulated. The formula derived considers stability, defined by both the ratio of extinct (E) to new $(\mathrm{N})$ genera, and the total output (G-E) to stable (S) genera, and is presented here as Taxonomic Flux:

$$
\text { Flux }=\frac{G-E+N+S}{S+G[(E+S) /(N+S)]}
$$

where,

$$
\begin{aligned}
& G=\text { Genera } \\
& E=\text { Extinct Genera } \\
& N=\text { New Genera } \\
& S=\text { Stable Genera (See text for definition) }
\end{aligned}
$$

and, all 4 parameters are from the same time step $(\mathrm{t})$.

The four parameters G, E, N and S are major dynamics observed in stratigraphic range data. Each has subcomponents, however, which can be isolated algebraically due in part to the definition of stability. The subcomponents resolved become: 
$\mathrm{G}_{\mathrm{p}}=$ Genera previous, the number of entering the time step, Input

$$
\mathrm{G}_{\mathrm{p}}=\mathrm{G}-\mathrm{N}
$$

$\mathrm{E}_{\mathrm{p}}=$ Extinct previous, the number of $\mathrm{G}_{\mathrm{p}}$ which went extinct

$$
\mathrm{E}_{\mathrm{p}}=\mathrm{G}-\mathrm{N}-\mathrm{S}
$$

$\mathrm{N}_{\mathrm{e}}=$ New extinct, the number of new originations that went extinct

$$
\begin{gathered}
\mathrm{N}_{\mathrm{e}}=\mathrm{N}-\mathrm{G}+\mathrm{E}+\mathrm{S} \\
\mathrm{N}_{\mathrm{e}}=\mathrm{N}-\mathrm{N}_{\mathrm{s}}
\end{gathered}
$$

$\mathrm{N}_{s}=$ New survivors, new originations surviving into next interval

$$
\begin{gathered}
\mathrm{N}_{\mathrm{s}}=\mathrm{G}-\mathrm{E}-\mathrm{S} \\
\mathrm{N}_{\mathrm{s}}=\mathrm{N}-\mathrm{N}_{\mathrm{c}}
\end{gathered}
$$

$\mathrm{O}=$ Output, the total number leaving time interval, $\mathrm{S}+$ $\mathrm{N}$ s or $\mathrm{G}-\mathrm{E}$

$$
\mathrm{G}=\mathrm{S}+\mathrm{N}_{\mathrm{s}}+\left(\mathrm{N}_{\mathrm{e}}=\mathrm{E}_{\mathrm{n}}\right)+\mathrm{E}_{\mathrm{p}}
$$

Proportional metrics for hypothetical data in Figure 1 are noted along with appropriate taxonomic flux values. It seems that taxonomic flux does indeed better describe system dynamics than traditional proportional metrics. Relative flux is determined by deviation from unity (1), with high values indicating diversity growth and low values (below 1) indicating diversity decline. Values that decrease to zero show complete extinction. Values approaching unity are indicative of equal extinction/ speciation $(\mathrm{E} / \mathrm{N})$ values, and/or dominant numbers of stable $(\mathrm{S})$ genera, relative to total $(\mathrm{G})$ genera.

The ratio of extinct $(\mathrm{E})$ to new $(\mathrm{N})$ genera appearances is calculated as $(E+S) /(N+S)$ to include timesteps which did not endure any cited extinction or speciation. Further, this term actually only affects the derived values when the stable components are few relative to total dataset size. Usually the effect realized by this fraction in the denominator is to provide a conservative value, especially with larger, more robust data sets. Conversely, this term also adds significance to smaller data sets.

Though we feel confident that taxonomic flux is a viable tool for describing the degree and direction of relative diversity change, we also realize that taxonomic flux has some limitations. An important outcome of the resolution of the $\mathrm{N}, \mathrm{E}, \mathrm{S}$ and $\mathrm{G}$ parameters into subcomponents shows that new $(\mathrm{N})$ and extinct (E) values actually share a subcomponent: $E=N_{c}+E_{p}$ and $N$ $=\mathrm{N}_{\mathrm{e}}+\mathrm{N}_{\mathrm{s}}$. This has important implications. First, it may explain the close approximation of New to Extinct values so often observed in the fossil record. But for this study, it means that taxonomic change that is neutral turnover, i.e. conditions of $\mathrm{E}=\mathrm{E}_{\mathrm{n}}=\mathrm{N}=\mathrm{N}_{\mathrm{e}}$ will be depicted as stable. This is because no stable members are affected; that all the new originations became extinct. This dilemma can be corrected however, if we consider what volatility means.

In such neutral turnover conditions divergence from overall stability is not realized with taxonomic flux.
There is, however, an increase in dataset size (G). Thus, volatility should include all the new and extinct that changed relative to the sample, G. Simply put, volatility is the opposite of stability, and the proportion of volatile taxa for a given group becomes:

$$
\text { Volatility }=(\mathrm{G}-\mathrm{S}) / \mathrm{G}
$$

This version of volatility also produces sensible results, always being a positive number which ranges from zero, no activity, to $100 \%$, if all membership has changed. As opposed to Gilinsky's $(1994,1998)$ metric, this measure of volatile taxa need not consider taxa longevity, or otherwise become a cumbersome and timedependent variable. We should note that this metric is similar, though not identical to turnover, as put forth by Russell (1998). Russell's metric merely sums both New and Extinct members, however, our version of volatility accounts for the $\mathrm{N}_{\mathrm{e}}$ values which are common to both New and Extinct taxa. Thus, Russell's turnover metric actually inflates the true dynamic of turnover, whereas our volatility assesses the proportion of taxa which do indeed change.

\section{METHODS}

This study will analyse a genus-level Cenozoic marine invertebrate data set representing several ordinal members of the Class Echinoidea and the Class Bivalvia. The echinoid database was compiled from Kier and Lawson's (1978) citation index 1924-1970. New citations gleaned from literature 1970-1996 were also obtained. The Bivalvia data was compiled from The Treatise of Invertebrate Paleontology (Cox, 1969). It should be stressed that this database is for comparative purposes only. The quality of Durham's data (1966) along with the purified Kier and Lawson (1978) data, are dated and proper taxonomy or actual ranges may be questionable. Thus, it is not our intent to make firm biotic interpretations, but rather, tentative conclusions to demonstrate the utility of taxonomic flux for cross-taxon study.

Each geological series, with the exception of the Paleocene and the Oligocene, was divided into lower-, middle-, and upper- intervals, in accordance with the geologic time scale as derived by Harland et al. (1990). The Paleocene and the Oligocene were divided into upper- and lower- series only. Conveniently, the approximate duration realized by this system is from 4 to 7 million years, which allows for reasonable comparison between each time step. This is necessary to reduce time components of sampling artifacts (Gilinsky, 1991; Foote, 1994), and is consistent with average marine invertebrate species longevity (Stanley, 1990). The rather short average species longevity also mandates that taxonomic analysis at this scale of temporal resolution be at generalevel or higher to reduce excess "noise" incurred by expected species turnover.

The data are plotted as time series, with fitted lines 


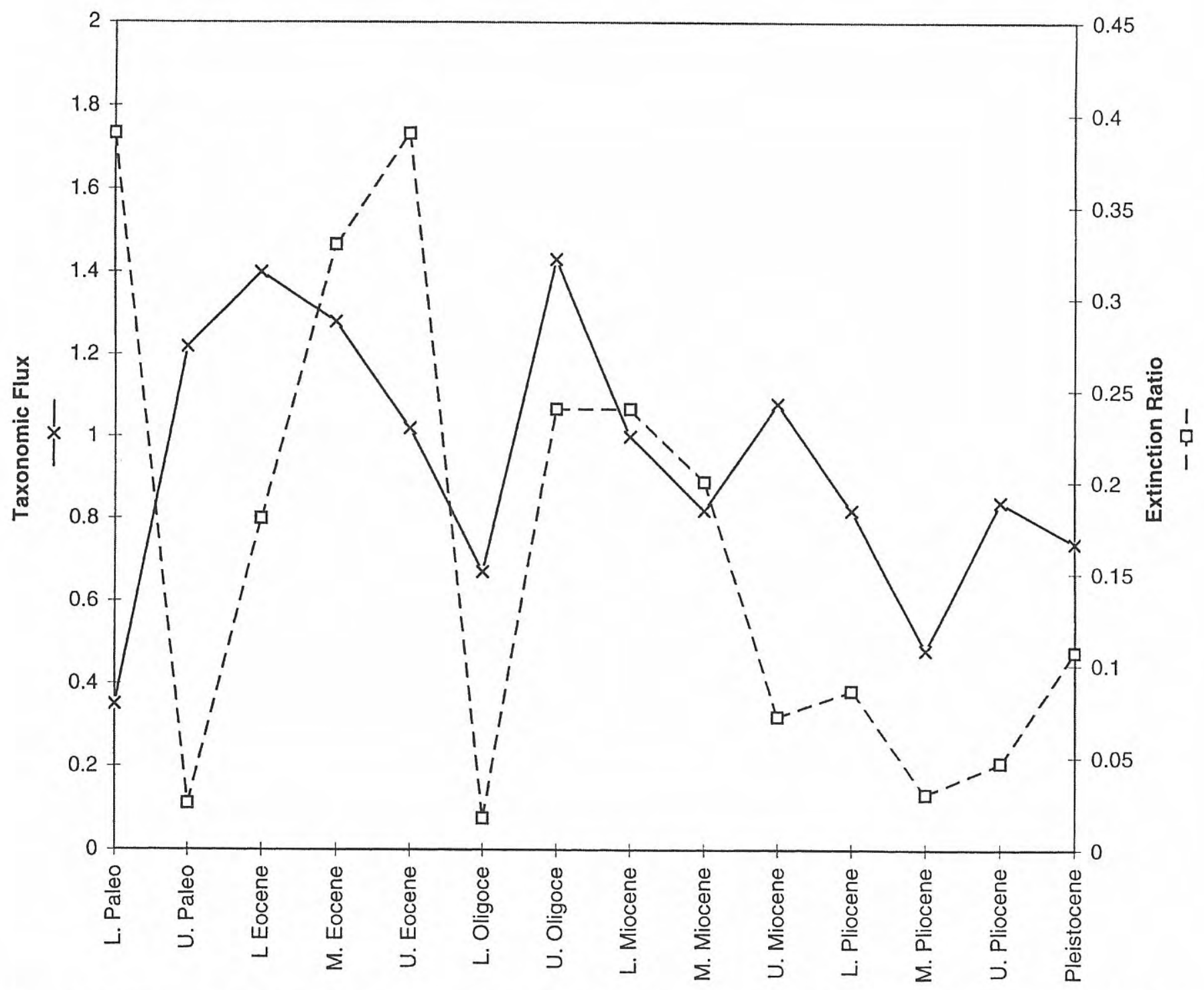

Figure 2. Taxonomic flux values as compared to extinction values for the echinoid orders considered in this study. Flux values are plotted on the first $y$ - axis; extinction values on the second $y$ - axis. Diversity decline, as depicted by flux only occurs at values below 1 . Decreasing flux values greater 1 mark changes in diversification rates, not diversity decline which is depicted by values falling below 1 . Note the disparity between apparent extinction rates and actual diversity patterns as shown by taxonomic flux. As would be expected there is some relationship between "high" extinction rates and diversity trends, but note that low extinction can also be correlated with flux decrease (L. Oligocene, M. Pliocene) while high extinction can be correlated with increasing diversity (U. Oligocene).

between data points. This aids in comparison of genera trends within the orders. Likewise, such curves also allow for comparison with palaeo sea surface temperature curves (Crame, 1993) as a proxy for environmental gradient. The choice of sea temperature for forcing function is based upon the assumption that marine organisms would respond to changes in ocean temperature regimes. This observation has been documented for echinoids previously (McKinney et al., 1992). We recognize, though, that many variables can influence sea temperature. It is our intent, however, to determine if these groups respond similarly to such a major environmental gradient or whether they respond consistently among themselves.

\section{RESULTS AND DISCUSSION}

In an earlier study examining echinoid trends (Dean, 1997; Dean and McKinney, 1997), the average taxonomic flux values for genus-level dynamics of all Cenozoic echinoid orders were calculated and compared to computed extinction ratios (Fig. 2). This previous research illustrates the wide disparity between assessing relative flux (1st y-axis) versus extinction ratios (2nd yaxis). As plotted, we see that diversity has experienced major movements of overall growth and decline. Flux values, indicate for much of the Cenozoic, average echinoid diversity has increased, with several drops diversity at the Eocene-Oligocene, Middle Miocene, and 


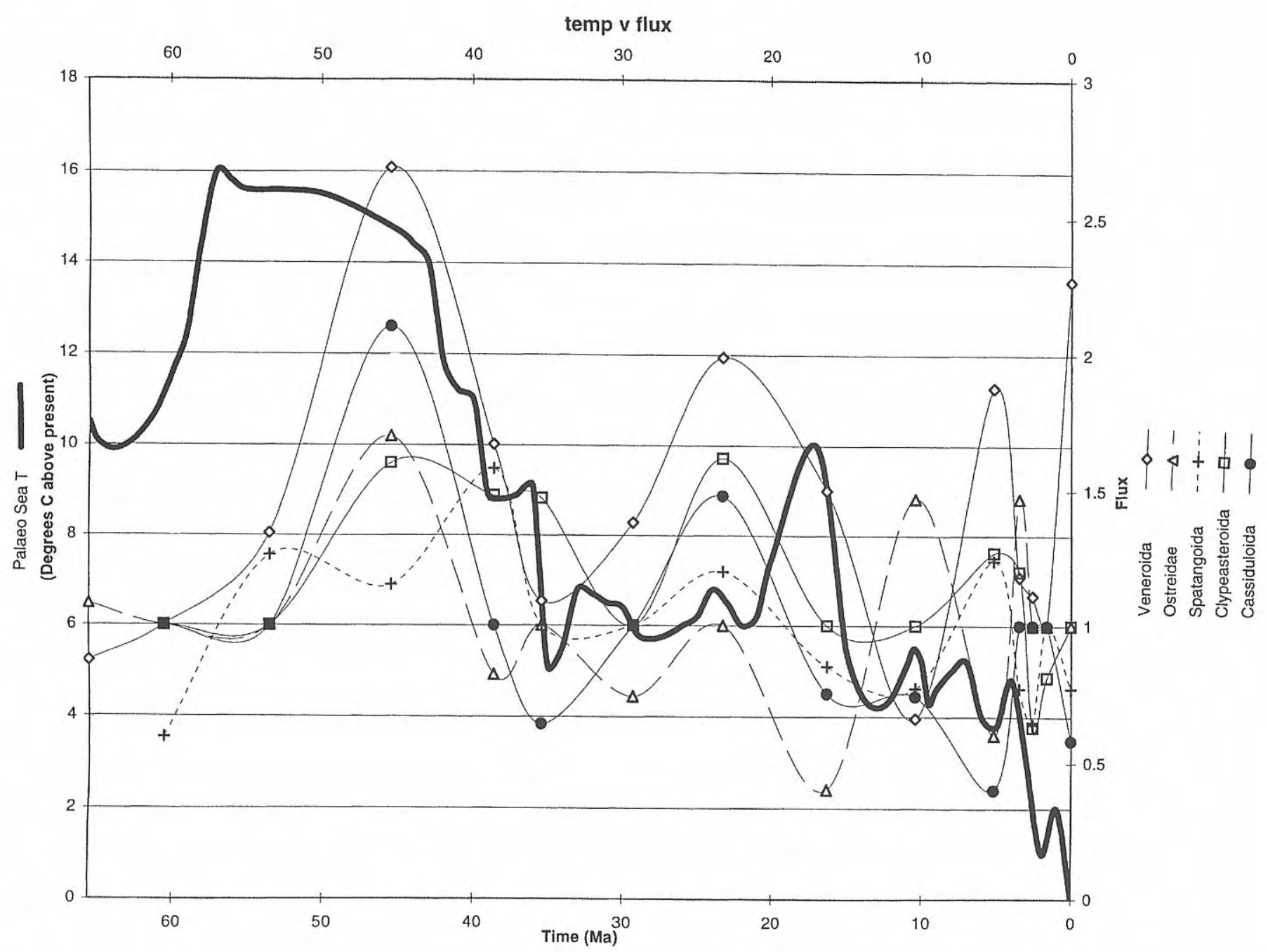

Figure 3. Taxonomic flux values of all groups in this study as plotted against palaeo sea surface temperature (after Crame, 1993). Note the diversity increase when temperature is stable and also the diversification decrease towards the present as sea surface temperature values fluctuate.

Middle Pliocene. These diversity decreases are real, as confirmed by flux. Though the connected data points do show decreasing values at other intervals in this time series, these are still periods of taxonomic growth unless they fall below 1. Thus in spite of the appearance of decreasing diversity with the downward movements, what we are actually observing is a decrease in diversification rates. This is easily resolved since diversification is known to proceed at exponential rates, but, must eventually slow down, as is depicted by flux.

When compared to extinction ratios, we see that negative flux $(<1)$ is only loosely correlated with high extinction. High flux values $(>1)$ are observed with very low proportional extinction during the Paleocene rebound, as well as the Upper Miocene and Pliocene intervals. But high flux values are also associated with high extinction in the late Eocene and Oligocene as well. Correlation coefficients between extinction ratio and flux confirm this disparity yielding $r$-values of less than 0.3 (0.299). This indicates that taxonomic flux is able to capture more evolutionary dynamics that extinction. In fact, the antithetical movements between flux and extinction may be related to changes in speciation rates relative to extinction rates (Foote, 1994). Furthermore, the lack of major diversity swings congruent with extinction fluctuations is likely attributed to the proportion of stable genera which does influence flux values. Additionally, high speciation values may also offset the net effect of high extinction in these cases.

An interesting outcome of the initial research is the ability to make comparisons of genus-level dynamics between the echinoid orders. One such comparison is presented here (Fig. 4b) which shows documented biotic interaction evident with the flux method. In the Australian fauna, niche replacement from cassiduloids to clypeasteroids has been postulated for the lower Eocene. The cassid gastropod is thought to have originated during the Eocene, specifically targeting the cassiduloids. This effect, along with physical evidence of predation has been observed in Tertiary Australia (McNamara, 1990; 1994), where it is believed that Clypeasteroida were able to benefit at the expense of the Cassiduloida, both of 

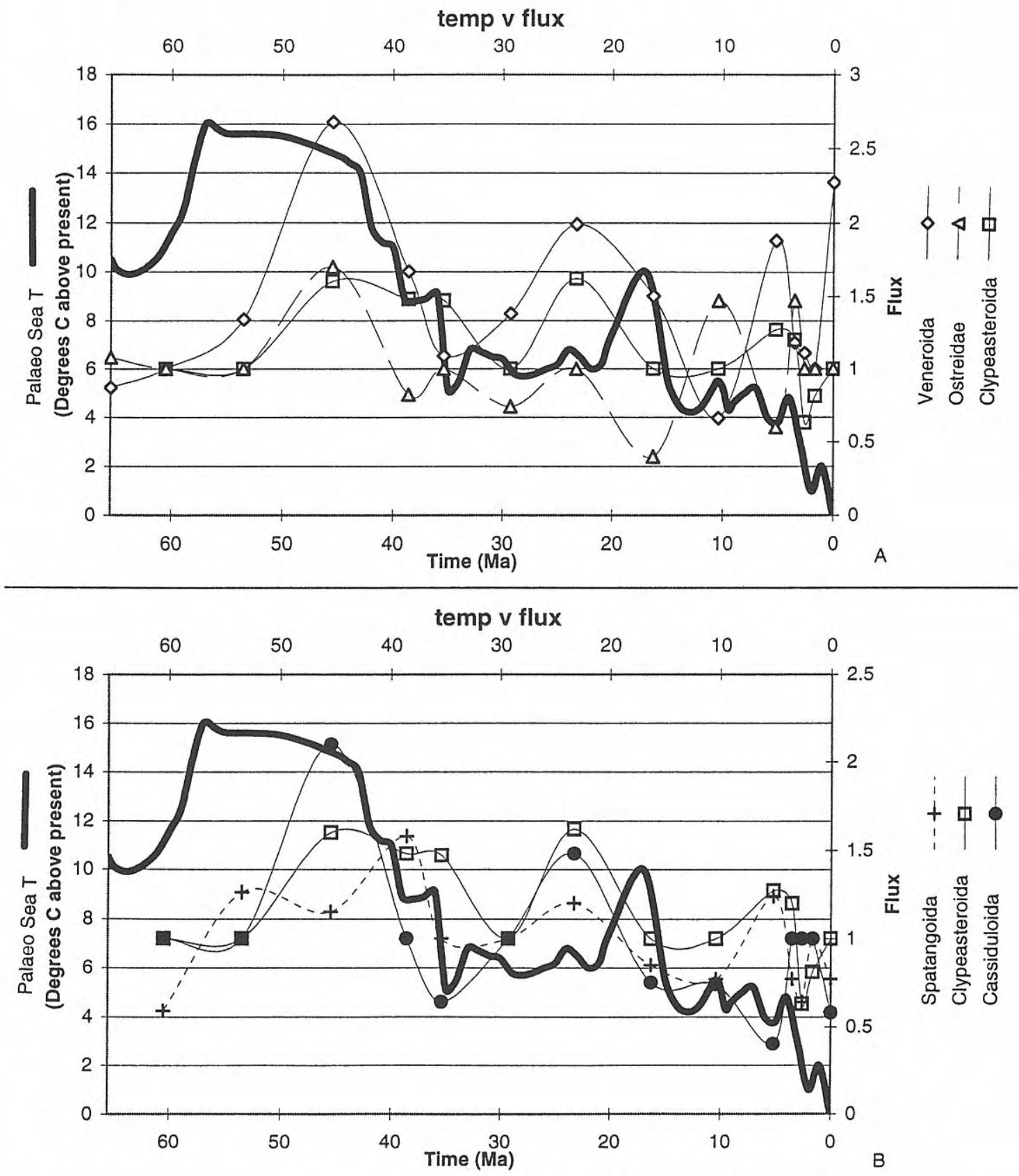

Figure 4. Individual plots of various taxa as compared against palaeo sea surface temperature. a.) Veneroida versus Clypeasteroida. Note similar flux trend though these belong to completely different orders. Note, however, the trends of the bivalves Ostreidae and Veneroida. Though both belong to the same class of molluscs, relative differences in flux values may be related to differences in habitat and niche occupancy. b.) Several echinoid orders. Note the increase of clypeasters at the expense of the cassiduloids around $40 \mathrm{Ma}$. This may be related to the effects of selective gastropod predation of the cassiduloids, as has been previously reported (See text). The deep water echinoid orders, both of which seem to have similar diversity trends. These graphs suggest that diversity dynamics may be related to habitat/niche control and not taxonomically clustered.

which share similar ecospace. This trend at about $40 \mathrm{Ma}$ is evident with flux, which depicts Clypeasteroida as steadily diversifying at this time. Flux graphs of cassiduloid and clypeasters show an inverse behaviour during this time. A similar pattern between cassiduloids and clypeasters is observed in the Upper Eocene, which is also the time cassid gastropods are first observed in the global fossil record (McNamara, 1994). These strong correlations between this methodology and observations from other, independent research confirm the validity and usefulness of using taxonomic flux to measure and interpret the fossil record.

In a subsequent analysis we compared the genuslevel flux of the Class Bivalvia, orders Veneroida and 
Ostreidae, with the Class Echinoidea, orders Spatangoida, Clypeasteroida, and Cassiduloida to palaeo sea temperature (Fig. 3). Our interpretation indicates a correlation between temperature and diversity, with $\mathrm{r}=$ 0.48 for all taxa plotted against palaeo sea surface temperature. While the derived $\mathrm{r}$-value is not exceedingly robust, this should not be too surprising. First, as stated previously, many other variables influence sea temperature. Second, other research has noted a delayed recovery between extinction events and subsequent diversification (Stanley, 1990; Kirchner and Weil, 2000). Thus even at the resolution of series-level data, it may be unrealistic to expect an immediate biotic response, especially for taxa recovery. The visual data presented (Figs. 3 and 4) do indicate a response to sea temperature albeit with some phase shift between the temperature and flux curves. The major periods of rapid ocean cooling roughly coincide with the upper Eocene and lower Pliocene diversity decline (Sepkoski, 1995).

A visual comparison of the flux curves shows that the taxa respond differentially to this gradient. Two orders, however, seem to respond consistently throughout the whole of this study: Veneroida, "the clams", and Clypeasteroida, "the sand dollars" (Fig. 4a), both of which are mobile and occupy a similar niche in nearshore, shallow water, sandy environments. It is possible that the sea temperature decline at around $47 \mathrm{Ma}$ and $20 \mathrm{Ma}$ could also be associated with Eocene glaciation (Follmi, 1995) and hence, sea level decline. Thus, more shelf area is exposed with sea level reduction which would also increase the baseline gradient and erosion. These two factors may provide more potential area, and perhaps more coarse substrate to enhance habitat requirements. The positive flux trends which depict growth are followed by flux values which move towards one, or stability. Thus, the fall in sea temperature does not seem to drastically affect the clams or sand dollars, which are able to preserve diversity, though with diminished taxonomic growth rates. In addition to substrate control affecting the nearshore habitat, the relative success of these two groups may also be related to their mobility.

Ostreidae are also nearshore dwellers, but, though oysters disperse well via planktic larvae, they generally have specific salinity requirements and are always sessile as breeding adults (Clarkson, 1993). The interpreted trend appears be dominated by declining behaviour in the face of environmental change, which contrasts with the flux of their sister bivalve clade, Veneroida (Fig. 4a). In fact the only two "growth" peaks were seen in i) the Paleocene, when all groups were recovering from the end Cretaceous extinction, and, ii) the slight increase after the Miocene event, when average temperature makes a moderate rebound after dropping some $8^{\circ} \mathrm{C}$. It seems reasonable to expect the nearshore, sessile fauna to be susceptible to gradients that would rapidly alter available habitat. This may be borne out by the observation that Ostreidae do seem to recover, albeit slightly, during the more extended periods of ocean temperature stability at $38-20 \mathrm{Ma}$ as well as the minor temperature fluctuations at $15-8 \mathrm{Ma}$.
Spatangoida, often described as deep water, deep burrowers (Smith, 1984), have somewhat similar Flux to that of Cassiduloida, which are also deep water but shallow burrowers (Fig. 4b). Though both showed some Paleocene rebound, Cassiduloida diversity rose dramatically, then declined, while Spatangoida showed a depressed recovery, yet continued to rebound well into the Eocene. This differential between Cassiduloida and the other echinoids has been attributed to predation factors, as discussed above.

After about $30 \mathrm{Ma}$, however, Spatangoida and Cassiduloida seem to stabilize in unison, and remain somewhat consistent in response to inferred sea temperature change. Both groups (Fig. 4b) seem to have declined at a temperature of $10^{\circ} \mathrm{C}$ above present, diversifying only when environmental conditions are stable for extended periods of time. The marked decline of the deep water fauna (Fig. 4b) after the $10-8^{\circ} \mathrm{C}$ above present temperature decrease (35 $\mathrm{Ma}$ and $18 \mathrm{Ma}$ ) may indicate a threshold value for the deep water groups, since they both remain depressed today, when compared to their past diversity. Deep water habitat as a control is not unequivocal, though. Spatangoidoida also show some correlation with the other shallow burrowers, Clypeasteroida and Veneroida (Fig. 3), indicating that substrate availability, possibly induced by changes in sedimentation, may also be a factor.

\section{CONCLUSION}

The results of this research indicate that taxonomic flux is an appropriate tool for capturing evolutionary dynamics. Unlike proportional extinction or speciation metrics, this methodology is based upon relative growth or decline as the system deviates from stability. Relative measurements, such as flux, can be used to compare taxa of differing sizes since we are considering several variables simultaneously. This, in turn, not only normalizes our data to sample size, but also weighs the proportion of change to the stable taxa. Thus, we are able to reduce some of the numerical sampling biases associated with data sets of differing sizes. No net change in taxa diversity equals perfect stability or one. Potentially unlimited growth is allowed via taxonomic flux, however, extinction at any point in time can only be $100 \%$. This aspect of diversity decline is also depicted by our metric and lends credence to its utility.

Trends elucidated by flux analysis are also consistent with established data, which indicate diversity declines at the Eocene-Oligocene transition and Middle Miocene. The strong relationship between the marine invertebrate biota and inferred palaeo sea surface temperature changes further strengthens the validity of this metric. Additionally, the apparent biotic interaction between the Cassid gastropod and Cassiduloida is evident here as well. The close approximation between our data and that of independent research confirms that this metric is a viable means for palaeontological studies. In fact, the cross-taxon data presented here does allow for some 
interpretation, allowing at least, limited identification of habitat control or organism mobility on influencing diversification trends. Though we are firm in our belief that taxonomic flux can be used for such cross-taxon diversity study, we also present an alternate form of volatility, which can measure the proportion of both new and extinct taxa relative to sample size. Much future potential may rest in the ability to modify this flux metric for use in modern ecological studies, providing a link between palaeontological observations to diversity problems of the Recent.

\section{BIBLIOGRAPHY}

Brett, C.E., Ivany, L.C., and Schopf, K.M. 1996. Coordinated stasis; an overview. Palaeogoegraphy, Palaeoclimatology, and Palaeoecology, 127, 1-20.

Clarkson, E.N.K. 1993. Invertebrate Paleontology and Evolution. $3^{\text {rd }}$ Ed. Chapman and Hall, London, 323 pp.

Cox, L.R. 1969. Bivalvia. In: Treatise on Invertebrate Paleontology, Part N, vol. 2 (Ed. R. C. Moore). University of Kansas Press, Lawrence, $951 \mathrm{pp}$.

Crame, J.A. 1993. Latitudinal range fluctuations in the marine realm through geologic time. Tree, 8, 162-164.

Dean, G. 1997. Evolutionary Flux in Fossil Echinoids: New Metrics for Old Dogmas. Master's Thesis, University of Tennessee, Knoxville, 153 pages (unpublished).

Dean, G. and McKinney, M.L. 1997. Taxonomic flux in fossil echinoids: New metric for old dogmas. GSA Abstracts with programs, 1997 Salt Lake City, 29(6) A342.

Demetrius, L. 1997. Directionality principles in thermodynamics and evolution. Proceedings of the National Academy of Science, 94, 3491-3498.

Eble, G. 1999. Paleodiversification; comparing lands and seas. Geobios, 32, 223-234.

Follmi, K. 1995. 160 m.y. record of marine sedimentary phosphorus burial: Coupling of climate and continental weathering under greenhouse and icehouse conditions. Geology, 23, 859-862.

Foote, M. 1994. Temporal variation in extinction risk and temporal scaling of extinction metrics. Paleobiology, 20, 424-444.

Gilinsky, N. J. 1991. The pace of taxonomic evolution. In: Analytical Paleobiology: Short Courses in Paleontology 4, (Eds. N. Gilinsky and P.W. Signor). The Paleontological Society, Knoxville, TN, 157-174.

Gilinsky, N. 1994. Volatility and the Phanerozoic decline of background extinction intensity. Paleobiology, 20, 445458.

Gilinsky, N. 1998. Declining taxonomic turnover in geologic time. In: Biodiversity Dynamics: Turnover of populations, taxa and communities (Eds. M.L. McKinney and J.A. Drake). Columbia University Press, New York, 162-186.

Gilinsky, N. and Good, I. 1991. Probabilities of origination, persistence and extinction of families of marine invertebrate life. Paleobiology, 17, 145-166.

Harland, W.B., Armstrong, R.L., Cox, A.V., Craig, L.E.,
Smith, A.G., and Smith, D.G. 1990. A Geologic Time Scale. Cambridge University Press, Cambridge, 263 pp.

Jablonski, D. 1995. Extinctions in the fossil record. In: Extinction Rates (Eds. J.H. Lawton, and R.M. May). Oxford University Press, Oxford, 25-44.

Kier, P.M. and Lawson, M.H. 1978. Index to living and fossil echinoids, 1924-1970. Smithsonian Contributions to Paleontology, 34, $182 \mathrm{pp}$.

Kirchner, J.W. and Weil, A. 2000. Delayed biological recovery from extinctions throughout the fossil record. Nature, 404, 177-180.

Koch, C.F. 1991. Sampling from the fossil record. In: Analytical Paleobiology: Short Courses in Paleontology 4 (Eds. N. Gilinsky, and P.W. Signor). The Paleontological Society, Knoxville, TN, 4-18.

McGhee, G.R. 1996. The Late Devonian Mass Extinction. Columbia University Press, New York, 303 pp.

McKinney, M.L. 1990. Trends in body-size evolution. In: Evolutionary Trends (Ed. K.J. McNamara). Belhaven Press, London, 75-118.

McKinney, M.L. 1995. Extinction selectivity among lower taxa: gradational patterns and rarefaction error in extinction estimates. Paleobiology, 21, 300-313.

McKinney, M.L. and Drake, J.A. (Eds.) 1998. Biodiversity Dynamics: Turnover of populations, taxa and communities. Columbia University Press, New York, $528 \mathrm{pp}$.

McKinney, M.L., McNamara, K.J., Carter, B.D., and Donovan, S.K. 1992. Evolution of Paleogene Echinoids: A global and regional view. In: Eocene-Oligocene Climatic and Biotic Evolution (Eds. D. Prothero and D. Berggren). Princeton. University Press, Princeton, 349367.

McNamara, K.J., 1990. The significance of gastropod predation to patterns of evolution and extinction in Australian Tertiary echinoids. In: Echinoderms through time. Proceedings of the eighteenth international echinoderm conference (Eds. B. David, A. Guille, J. Feral, and M. Roux). Rotterdam, 785-793.

McNamara, K.J. 1994. Diversity of Cenozoic marsupiate echinoids as an environmental indicator. Lethaia, 27, 257-268.

Palmqvist, P. 1993. Trophic levels and the observational completeness of the fossil record. Revista Española de Paleontología, 8, 33-36.

Raup, D.M. 1991. The future of analytical paleobiology. In: Analytical Paleobiology: Short Courses in Paleontology 4. (Eds. N. Gilinsky and P.W. Signor). The Paleontological Society, Knoxville, TN, 207-215.

Rosenzweig, M.L. and McCord, R.D. 1991. Incumbent replacement: evidence for long-term evolutionary replacement. Paleobiology, 17, 23-27.

Russell, G.J. 1998. Turnover dynamics across ecological and geological scales. In: Biodiversity Dynamics: Turnover of populations, taxa and communities (Eds. M.L. McKinney and J.A. Drake). Columbia University Press, New York, 377-404.

Sepkoski, J.J. 1995. Patterns of Phanerozoic Extinction: A perspective from global databases. In: Global Events and Event Stratigraphy in the Phanerozoic (Ed. O. Walliser). 
Springer-Verlag, New York, 35-52.

Smith, A.B. 1984. Echinoid Palaeobiology. Allen and Unwin, London, 190 pp.

Stanley, S.M. 1990. The general correlation between rate of speciation and rate of extinction. In: Causes of Evolution: a Paleontological Perspective (Eds. R.M. Ross and W.D. Allmon). University of Chicago Press, Chicago, 103-127.

Manuscrito recibido: 24 de febrero, 2000 Manuscrito aceptado: 30 de octubre, 2000 